\title{
Reframing forensic science and criminology for catalysing innovation in policing practices (opinion paper)
}

Olivier Ribaux, Ecole des Sciences Criminelles, Faculty of Law, Criminal Justice, and Public Administration, University of Lausanne

Ribaux, O. (2017) 'Reframing Forensic Science and Criminology for Catalyzing Innovation in Policing Practices', Policing: A Journal of Policy and Practice 13 (1), 5-11, 10.1093/police/pax057

Abstract The current social and economic life is immersed in new spaces enabled by ubiquitous technological infrastructures. Crime systems of different types emerge from these changes. They are more global, larger in scale, complex, adaptive, and difficult to decipher. Traditional reactive strategies based on law enforcement and prosecution on a case-by-case basis, no longer function in this new context. The police must adapt but they meet difficulties in taking distance and conceptualizing the changes. This opinion paper explains why an academic department housing,both criminology and forensic science, is in good position for addressing these new issues in policing. The necessity to build approaches around physical and massively generated digital traces, provides the rationale for this alliance. Leads about how police professionals can be educated and trained for facing this new situation are also suggested.

\section{Introduction}

Universities defend scientific freedom unequivocally. This basic principle mainly guides my action, as director of a department (School). My role is to create the most favourable conditions by which researchers can individually develop their own projects independently, and assert their distinctive identity. The department itself, as an entity, must also display an identity. It cannot be defined as the sum of the individual contributions of renown persons. Something must keep the whole together.

Systematically searching for tenets is indispensable for adapting the structure, and identifying promising areas for new developments. This is particularly relevant and exciting in the vast, scattered, and rapidly evolving fields of criminology and forensic science. Both are interdisciplinary in nature, that is, they require collective endeavour, and the development of transdisciplinary frameworks.

An organisation hosting together criminology and forensic science has the perfect conditions for addressing current challenges in policing. Indeed, we are immersed in global numerical 
environments that are transforming the nature of spaces where daily social and economic activities take place. Smart and connected objects (cars, home, phones - loT $^{1}$ ) amplify this movement. Technology-enabled crime is changing in scale. It is more global and networked. It is poorly defined by Law, more difficult to detect, more complex, and more adaptive. Policing these new spaces means reinterpreting the complex "security / justice / liberty", as well as initiating a profound renovation of existing approaches.

The main commercial figures, that colonise these spaces, trace human activities massively ${ }^{2}$. How new global and interconnected crime mechanisms can be deciphered and disrupted, depends on how we are able to detect, recognise, interpret, and link relevant traces. This is exactly where forensic science and criminology can join for making emerge innovative models, methods, and tools.

\section{Reason for changes}

Changes in policing are largely inhibited by established paradigms, current academic structures, and a ubiquitous police culture.

Forensic science generally restricts itself to supporting administrative, criminal, or civil courts in decision-making. Many controversies have recently been raised as to the appropriate way to bring information before a Court of law (NAS 2009; PCAST 2016). Documented cases of miscarriages of justice focus all the attention. The rhetoric is, occasionally, violent ${ }^{34}$. Forensic science is mostly reactive in face of those criticisms. Related researches are carried out in academic structures, but they are fragmented. They exist as the application/prolongation of branches of the fundamental sciences (e.g. chemistry, biology, information sciences) (Mennell 2006; Quarino and Brettel 2009; Roux and Robertson 2009). The divide translates directly into the daily life of traditional forensic laboratories. Forensic science struggles to

\footnotetext{
${ }^{1}$ IoT - Internet of Things

${ }^{2}$ The acronym GAFA (Google Apple Facebook Amazon) is used to designate the movement of plateforms that massively grasp traces from users.

${ }^{3}$ A wake-up call on the junk science infesting our courtrooms. Harry T. Edwards and Jennifer L. Mnookin Washington Post; September 20, 2016

${ }^{4}$ see for instance: British Journal of American Legal Studies, special issue : Criminal Justice and Forensic Science Evidence: Current Controversies, 4 (2), 2015
} 
install itself as an academic discipline intrinsically capable of deploying proactively a broader potential in policing.

Criminology is dispersed across many movements and controversies (Pease 2010). Debates are occasionally also violent or, at the other extreme, non-existent, when sub-communities consider that they have nothing in common. Tensions surrounding the definition of basic concepts, such as risk, security or policing, are pervasive. Criminology is also implemented in universities as the prolongation, and under the influence, of traditional disciplines (mainly sociology, law and/or psychology). There is evidence that nothing really innovative, concrete and useful to address new policing issues, emerged in recent times from the existing dialectics. Beyond significant exceptions (see e.g. (Pease 2010; Décary-Hétu and Dupont 2012; Broséus et al. 2017; Chan and Moses 2017)), contributors stay in their ideological silos, while the world changes dramatically (Dupont 2016).

I was excited to participate in the European Academy of Criminology meeting in Porto (ESC 2014) and the meeting of the Australian and New-Zealand Forensic Science Society in Auckland last year (ANZFSS 2016). I expected to learn a lot about the mechanisms behind modern crimes. I was also interested in how to expand the expression of identities and the notion of identification in the information society, as well as how to integrate the massive traceability intrinsic to numerical environments (see Casey and Jaquet-Chiffelle, this issue). Both conferences were excellent, very well organised, and the participation was massive. However, when it comes to these new challenges, I was really disappointed. Sessions that brought some information were rare and incredibly discrete: where are then those who study new crime problems and conceptualise in these areas? At least, I felt I was not at the right place to address issues related to policing the society we are now living in.

The police themselves should play a role for stimulating the debate. After all, they are directly confronted to the new realities, and are best placed to alert on the lack of knowledge and difficulties. There are at least three obstacles on this path: 
1. recent surveys show that a large proportion of new crime problems are no longer dealt with by the police: $99 \%$ of routine digital crimes appear to be unreported ${ }^{5}$. Not to mention other types of complex crime mechanisms that escape its coverage (e.g. complete areas in financial and economic crimes or many other multi-jurisdictional crime problems);

2. whatever the rhetoric, the police are still largely reactive, based on a case-by-case approach. There are many efforts in complying with established rules and procedures; there is not always real appetite to develop a vision, and adopt proactive policing style;

3. the police are still obstinately convinced that only policemen can deliver what they estimate themselves to be police tasks. Despite the evidence that a rapid and structured analysis of high volume of diverse digital data requires other types of aptitudes, knowledge, and, overall, a more structured and 'scientific' attitude. These capacities are not inherently available in a police system, even if there is no doubt that intern talents exist.

Confronted with an invasion of numerical data, a majority of organisations employs so called 'civilians' personnel. Their numbers have increase dramatically in these environments over the past fifteen years. This group of collaborators is, however, still perceived as a patchwork of auxiliary 'specialists' who will relieve the real police work from technical issues. They are not seen as key players, capable of developing a strategic vision of how to take advantage of innovative technologies and big data.

This inertia leaves a void that other communities, outside the police, tend to fill. Stakeholders offer many services for conducting private investigations, as well as for monitoring the web. Privatisation is taking a new turn. This is not about the future. This is rather an observation that reflects the current reality. Policing do not restrict to the police. A certain redistribution of tasks is inevitable, but the police must strive to keep in touch with the network of relevant, well-informed and well-equipped figures.

\footnotetext{
${ }^{5}$ See for instance https://www.ons.gov.uk/peoplepopulationandcommunity/crimeandjustice/bulletins/crimeinenglandand wales/previousReleases (accessed 14th of August 2017)
} 


\section{Addressing new spaces by connecting forensic science and criminology}

The three issues mentioned above should be addressed: (1) how to capture current crime problems, and make them explicit in size, extend, organisation, and evolution; (2) how to develop and implement in a more offensive way proactive styles of policing, based on partnerships and on frameworks for interpreting traces massively generated; and (3) how to educate future professionals for these purposes.

\section{Grasping the crime problem}

Traces of all sorts, as the remnant of a criminal activities, constitute frequently the necessary elementary information for detecting and analysing crime problems. Forensic case data (e.g. DNA, fingerprints, firearms, explosives, mobile phone data, vehicles) were central in the investigation and explanation of the terrorist attacks in Paris and Bruxelles. They were effectively the catalyser of the investigation by linking the cases. Beyond supporting police operations, they provided relevant insight about on how groups are structured and how they operate. It is, however, not clear how forensic science was recognised as a key investigative and intelligence provider in this case. Expressing the value of forensic science in policing is critical to the approach.

Forensic science was implicated differently in a recent study on the structure and the organisation of the market for opioids (essentially heroine). This research has been carried out in a region of Switzerland (Zobel et al. 2017). It provides a good example of how to integrate multiple perspectives and sources of data. This multi-dimensional approach increased dramatically knowledge about this type of illicit market. It exploited models and methods traditionally used separately in criminology and forensic science. It has been impressive to bring together political, social, and demographic data, police data (coming from investigations and from informants), wastewater analysis, chemical profiles of the seized substances, chemical profiles of substances found on used syringes, data coming from the dark web, as well as consumer surveys. It showed that the size, complexity, extend, and economy of trafficking was largely overestimated by the different figures participating to prevention and repression. Similar projects will be initiated on this basis. The data will be also compared internationally. This will be a further step towards the objective of providing a more global picture of the problem. 
The initial activity in such a study is to use the appropriate and distinct methodologies on each component of the puzzle. There are good research groups and professionals who practice at this level. However, each of the perspective adopted is too narrow to obtain a sufficiently complete picture. The complexity increases essentially at a second level, when the different sources are integrated, going beyond silos defended by the disciplines involved. This is a great merit of this study, which achieved its objective through a collective effort of the participants.

The case of illicit drug trafficking represents only a tiny part of the changes to be handled. It is a part of a broader family of problems related to other illicit markets (e.g. false ID documents, counterfeited goods) or repetitive crime problems. They still remain largely to be expressed.

Experience shows that very simple forensic comparisons occasionally catalyse the discovery of such complex crime systems. For instance, two false ID cards seized by the authorities, detected as similar, may point to same manufacturers. In turn, this result can uncover the activity of organised groups operating at an international level (Baechler et al. 2012). As another example, same pseudo used on different carding sites, or whatever other crimerelated forums, might also indicate common activities diluted throughout the web. Thinking transversally, some authors have conceptualise a generic forensic intelligence model, that allow to systematize such comparisons (Rossy et al. 2013; Morelato et al. 2014).

Such intelligence processes express how to take advantage of forensic science by detecting, collecting, observing, and comparing traces in a holistic way to provide an overall picture of the issue. A criminological contribution is obviously indispensable for completing the approach. Such a system of crime analysis is an important step forward in the creation of renewed and integrative models.

\section{Amplifying the movements toward proactive styles of policing}

The analysis of crime and disorders takes advantage of repetitions, concentrations and structured networks. For a long time, it has been demonstrated that certain criminal activities follow patterns that repeat in the future (Wortley and Mazerolle 2008; Boba 2009; Ratcliffe 2016). This was the reasons for moving to a more proactive style of policing. 
However, the turn was taken very timidly. It resided more in the rhetoric than in reality (Ratcliffe 2002).

It is now clear that a strategy focused on traditional reactive case-by-case investigations will no longer work to address new crime situations. Specific investigations remain useful mainly to provide explanations about what occurred, and to reassure the victims. From an utilitarian point of view, the pursuit might still create occasionally a deterrence or a neutralisation effect. Forensic science will still continue to plays its role at this level. However, it becomes clear that strategies need to change direction. A broader picture will allow tailored crime disruption, the devise of ways for reducing harm and reassuring the public, as well as for preventing crimes in new environments.

Forensic science brings its strength in investigating specific situations and in connecting the dots. Criminology possesses some keys for contextualising and interpreting new species of traces. It can also devise new research projects for evaluating what works and what fails when policing new environments (Dupont 2017). Together, they can then call for the appropriate methods and technologies for mining data (traces).

In an unstable and uncertain context, a policy window seems definitely open for the development of such proposals.

\section{Education and training}

If we agree with the above point of view, we must also question the type of education and training models to be developed, both in the academic and police communities. There is no single appropriate educational framework. It is clear, however, that traditional structures of forensic science and criminology, based on fundamental disciplines, do not provide an appropriate environment for this purpose.

Some characteristics of a combined model emerge:

- basic knowledge on crime theories, and on certain forms of criminality, are indispensable. The elicitation of terms such as security, risk and prevention, as well as the study of policing models are obviously part of this core criminological component. Objectives should be oriented toward motivating students to systematically turn toward gaining knowledge of the broad picture of crime systems, and developing critical judgement on available interpretations; 
- an introduction to Law provides other required contextual elements;

- general knowledge on forensic science and of its fundamental principles consist of a full part of the educational framework. Awareness of the variety of traces, including its new numerical species, is essential. In addition, particular attention needs to be paid to how they are generated, collected, analysed and interpreted in judicial and policing processes. It is an in-depth forensic science perspective that require solid fundamental knowledge in the basic sciences (information sciences, physics, chemistry, mathematics and statistics).

- the educational framework also aims at the development of skills for the use of computational models for crime and risk analysis, as well as for the processing of big data; methodological tools, quantitative and qualitative can also be addressed at this level.

- students should experience with technologies in an important part dedicated to solving real problems and exercises. Beyond, they are expected to remain highly adaptive. They must acquire the ability to distinguish the levels of genericity from models and techniques. If necessary, when in activity, these students should be able to return to this transversal, and more stable knowledge in order to choose in which direction to adapt and specialise in a new relevant direction;

- the development of soft skills allowing a cooperative and collective endeavour belongs eventually also to this ideal.

This is a very demanding education programme, far beyond what police schools generally require now. Nevertheless, this high level corresponds to the complexity of the new situation. The police have extensive experience in crisis management, operations, interviews and investigations. New models ask for something different: means of intervening in technology-based and gun-free spaces cannot be directly derived from a mere analogy with traditional physical situations.

\section{Conclusion}

Transcending dominant streams, both in terms of research and education, is needed to revamp policing models. The approach has its limits and commentators regularly express their scepticism. The problems to be addressed and the knowledge to be mobilised in order to maintain a global view on a wide range of problems are far too broad. The danger lies in 
the promises that would not be delivered. This is why collective problem solving remains a central attitude in the whole approach.

The academic role is also questioned (e.g. the university should not become a professional police school; it should keep its independency from other institutions). This is true that adopting such a line is not without such dangers. It is a never ending balancing act.

I believe however, in the strength of a configuration anchored in the so-called 'hard', formal and information sciences. It is important to maintain the effort, at a time when hard sciences are mostly abandoned by the younger generation. Students require some proof of social utility in the discipline they commit.

Our department has initiated a Master's degree in traceology and crime analysis, which is augmented by extensive research. It defines the dispositive to address challenges described in this paper. The reactions of some academic communities and potential employers are excellent. This course greatly expand the opportunities previously offered to separate communities of forensic science and criminology students.

Readers have the opportunity to make their own opinion throughout this special issue. But one thing seems clear to me: if we are recognised that we do things differently, it is evidence that we possess an identity.

\section{Bibliography}

Baechler, S., P. Margot and O. Ribaux (2012) 'Toward a Novel Forensic Intelligence Model: Systematic Profiling of False Identity Documents', Forensic Science Policy and Management Vol 3 no 2, 70-84

Boba, R. (2009) Crime Analysis with Crime Mapping, Sage, Los Angeles

Broséus, J., D. Rhumorbarbe, M. Morelato, L. Staehli and Q. Rossy (2017) 'A geographical analysis of trafficking on a popular darknet market', Forensic Science International Vol 277, 88-102, https://www.scopus.com/inward/record.uri?eid=2-s2.0$85020763245 \&$ doi $=10.1016 \% 2$ fj.forsciint $.2017 .05 .021 \&$ partnerlD $=40 \& \mathrm{md} 5=b 3 e 4 \mathrm{df0}$ 78bd48f914f3f172b4959e2d7

Chan, J. and B. L. Moses (2017) 'Making Sense of Big Data for Security', The British Journal of Criminology Vol 57 no 2, 299-319, http://dx.doi.org/10.1093/bjc/azw059

Décary-Hétu, D. and B. Dupont (2012) 'The social network of hackers', Global Crime Vol 13 no 3, 160-175, http://dx.doi.org/10.1080/17440572.2012.702523

Dupont, B. (2016) 'Des effets perturbateurs de la technologie sur la criminologie - Of the disruptive effects of technology on criminology', Revue internationale de criminologie et de police technique et scientifique no 3, 305-322 
Dupont, B. (2017) 'Bots, cops, and corporations: on the limits of enforcement and the promise of polycentric regulation as a way to control large-scale cybercrime', Crime, Law and Social Change Vol 67 no 1, 97-116, https://www.scopus.com/inward/record.uri?eid=2-s2.084990818458\&doi $=10.1007 \% 2 \mathrm{fs} 10611-016-9649$ $\underline{z \& p a r t n e r I D=40 \& m d 5=684 e 8746 e 887746 b b 855 c d 37 b 6 d d f f 6 f}$

Mennell, J. (2006) 'The future of Forensic and Crime Scene Science: Part II. A UK Perspective on Forensic Science Education', Forensic science international Vol 157, Supplement, S13-S20, http://www.sciencedirect.com/science/article/pii/S0379073805006948

Morelato, M., S. Baechler, O. Ribaux, A. Beavis, M. Tahtouh, P. Kirkbride, C. Roux and P. Margot (2014) 'Forensic Intelligence Framework. Part I: Induction of A Transversal Model by Comparing Illicit Drugs and False Identity Documents Monitoring', Forensic science international Vol 236, 181-190

NAS (2009) Strengthening Forensic Science in the United States: a Path Forward, National Research Council of the National Academies, National Academies Press, Washington D.C.

PCAST (2016) Forensic Science in Criminal Courts: Ensuring Scientific Validity of FeatureComparison Methods, Executive Office of the President President's Council of Advisors on Science and Technology Committee, Washington

Pease, K. (2010) 'Crime Science' in Shlomo G. Shoham, P. Knepper and M. Kett (eds), International Handbook of Criminology, CRC Press, Boca Raton, 3-22

Quarino, L. and A. T. Brettel (2009) 'Current Issues in Forensic Science Higher Education', Anal Bioana Chem Vol 394, 1987-1993

Ratcliffe, J. (2016) Intelligence-Led Policing, Willan, 2nd edition, Cullompton, UK

Ratcliffe, J. H. (2002) 'Intelligence-Led Policing and the Problems of Turning Rhetoric into Practice', Policing and Society Vol 12 no 1, 53-66

Rossy, Q., S. loset, D. Dessimoz and O. Ribaux (2013) 'Integrating Forensic Information in a Crime Intelligence Database', Forensic Science International Vol 230, 137-146

Roux, C. and J. Robertson (2009) 'The Development and Enhancement of Forensic Expertise: Higher Education and In-Service ' in J. Fraser and R. Williams (eds), The Handbook of Forensic Science, Willan Publishing, Cullompton, 566-595

Wortley, R. and L. Mazerolle, eds. (2008) Environmental Criminology and Crime Analysis, Willan, Cullompton, UK, Willan

Zobel, F., P. Esseiva, R. Udrisard, S. Lociciro and S. Samitca (2017) Le marché des stupéfiants dans le canton de Vaud: Les opioïdes., Addiction Suisse/Ecole des sciences criminelles/Institut universitaire de médecine sociale et préventive, Lausanne 